\title{
RE-USING HERITAGE ELEMENTS IN NEW BUILDINGS: CASES FROM THE UNITED ARAB EMIRATES
}

\author{
JIHAD AWAD \& BOUZID BOUDIAF \\ Ajman University, UAE
}

\begin{abstract}
"Presence of the past" is one of the basic principles of postmodern architecture and has been interpreted in many ways. A multitude of architects turned towards the past and found their references in heritage elements. While some inspired ideas from historic architecture, others copied or re-used elements and vocabulary from heritage architecture. This trend started as a response to the principles of the modern movement and international style which dominated for decades. Post the discovery of oil in the United Arab Emirates (UAE) the need to express globalization and modernization, considered as indicators of prosperity and development, was expressed in the construction of high-rises and towers made of glass. This radical change in the architecture of the built environment was far removed from the architectural heritage of the country, resulting in the loss of the value of a sense of place. As the value of heritage and culture has gained traction globally, there is now a growing trend calling for architecture that reflects a localized, unique identity of place. Architects in response have started to borrow and copy elements from historical styles, at times regional and at times from different historical periods and cultures. This trend can also be observed all over the UAE and might be referred to as the "Nationalization" of architecture. It is common sight to now see characteristic features and elements of traditional Emirati architecture copied and duplicated in various new buildings by purely "re-using" forms irrespective of different functional uses. The purpose of this paper is to highlight the visible transformation in the use of traditional, functional elements of building heritage as visual, symbolic elements of culture and identity in new buildings. The paper also elaborates on how the most dominant symbol of Emirati heritage and identity, the Barjeel (pl. Barajeel) or wind catchers, can be conspicuously seen not only in architecture but also in various other contexts.
\end{abstract}

Keywords: heritage, postmodernism, Gulf architecture, wind catchers (Barajeel), modernization, globalization, vernacular architecture, United Arab Emirates, identity.

\section{INTRODUCTION}

The United Arab Emirates (UAE) consists of seven emirates: Abu Dhabi, Dubai, Sharjah, Ajman, Umm al Quwain, Ras al-Khaimah and Fujairah. Prior to the oil boom the architecture of the Gulf region was heavily influenced by the harsh, desert environment. Houses were built from readily available coral stone and gypsum with distinct climatic, religious and socially responsive design features. Thick walls with high thermal mass, creation of narrow alleyways through close orientation of buildings, wind towers to accentuate wind movement in interior spaces, courtyards for privacy and to further improve the microclimate; were just some of these responsive design features [1]. Thus, the basis of the architecture and urban environment of the Gulf region was one that obtained its characteristics from the context of space; place. Bruno Zevi referred to space as the basis of architecture and stressed on architecture obtaining its characteristics from it [2].

Globalization and the need to replicate success through tried and tested methods has resulted in a culture of "copy" and imitation. The focus from cultural identity naturally shifted towards pursuance of global stature and economic prosperity. Vernacular structures were abandoned in favor of concrete structures and facades of glass [3]. Rapid economic and sociocultural changes due to newfound economic prosperity, contributed heavily to transforming the architecture of the built environment [4]. Buildings have translated into representative symbolic icons of progress and prosperity; Sheikh Zayed Road in Dubai is a prime example 
of such a symbol littered with glamorous, contemporary skyscrapers (Fig. 1). One of the most well-known examples of such an icon is the Burj Al Arab hotel by WS Atkins (Fig. 2), which was the initial push that put Dubai on the World map [5]. The architect of Burj Al Arab describes the search for an "iconic form" as the main driver behind the symbolic design [6].

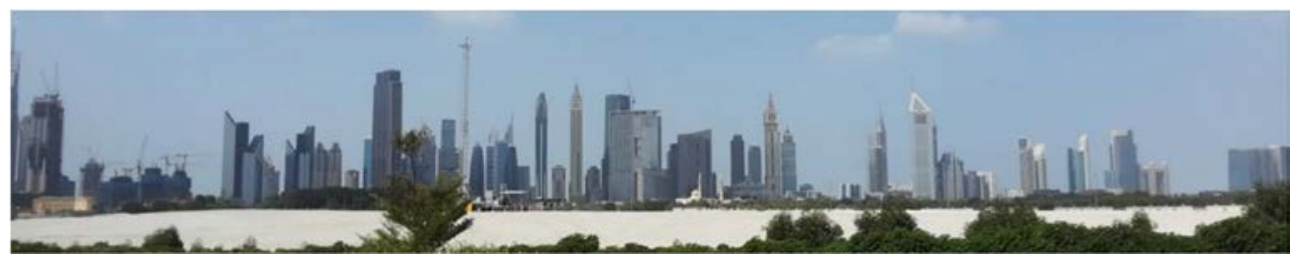

Figure 1: Sheikh Zayed Road and its eclectic collection of skyscrapers, Dubai. (Photo: Jihad Awad, 2019.)

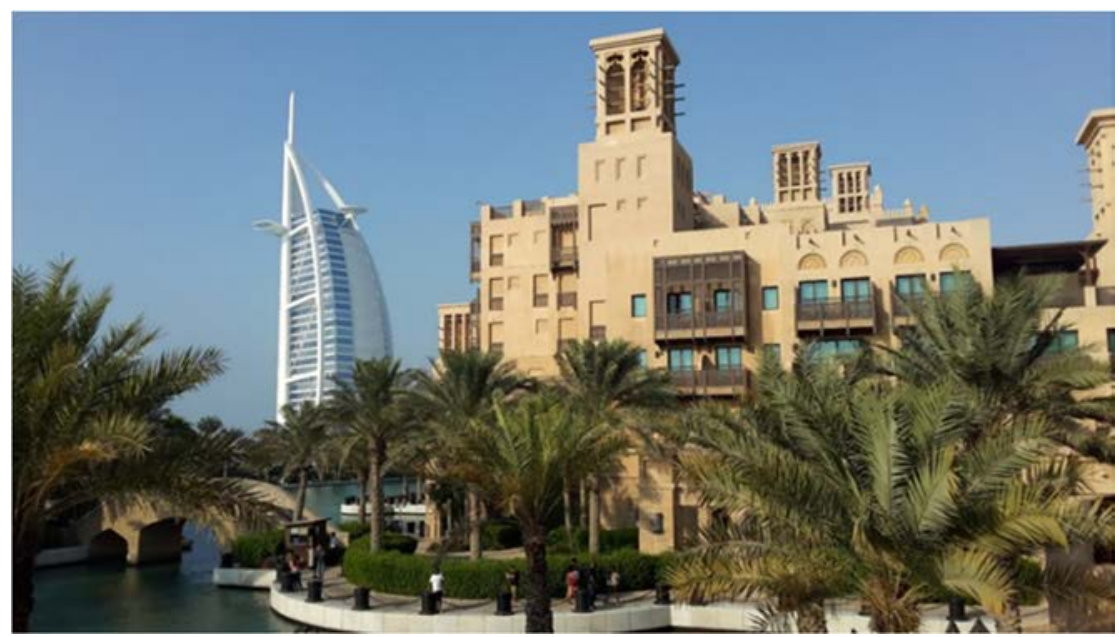

Figure 2: Dubai's contrasting, symbolic projects. Burj Al Arab (left) and Madinat Jumeirah (right). (Photo: Jihad Awad, 2019.)

The rush to replicate economic success through architecture has resulted in the hiring of the same architects with proven "brand value", who create similar buildings in their respective signatory styles, resulting in the creation of "uniform" and "indistinctive" cityscapes [7]. "Buildings, just like generic products, fulfil needs, but architecture fulfils desires" [8]. The intrinsic link between architecture and the image of a global, modern society resulted in a complete disregard for the cultural, heritage and climate responsive values of vernacular architecture, over glamorized modern, western design ideologies that didn't pay any respect to the context of place [3]. Dubai, for example, is a prime example of extreme urbanism. An emphasis on themed projects has transformed the role of architecture into a continuous interplay of special effects and scenography [6].

The nineties saw a visible attempt to shift towards authenticity. An emphasis on historical identity, heritage conservation and local culture has led to the development of various projects aimed at promoting vernacular architectural practices and immersive local cultural 
experiences. Klingmann in her book, Brandscapes, notes that "authentic solutions" should be rooted firmly into the "DNA" of the "local character" of the city in order to tap into unique socio-economic potentials that are lasting [7]. Various projects have been realized in this regard; Al Bastakiya, Al Seef, Hatta Heritage Village, to name a few. The overarching goal to revitalize architectural heritage of the past was imbued through use of architectural styles and features to stress national identity. Many of the unapologetically modern buildings that had been constructed in the seventies were replaced by buildings that featured architectural elements relevant to the region. Modern amenities, such as, air conditioning and modern construction methods and materials, such as, reinforced concrete, were not sacrificed. Mahgoub notes that while some of these attempts to return to authenticity were successful while others were overdone [4].

\section{METHODOLOGY}

This paper is based on the observation and investigation of hundreds of buildings in major cities of UAE. A qualitative approach has been used for this study.

\section{THE CALL TOWARDS AUTHENTICITY}

The last quarter of the 20th century witnessed a global rise in the call towards authenticity and a rejection of the blatant functionalism of modernism. Architects took inspiration from the past and various nuanced and loud references to the past were made in the form of arches, domes and other historical elements in new buildings. Postmodernism due to its inference to the past made it possible to adapt modern principles and techniques while ensuring their contextual value remained uncompromised [9]. Charles Jencks re-defined Post-Modernism as "an eclectic mix of traditional or local codes with Modern ones" [10].

The architecture of the UAE has always been a topic of intense debate with often, paradoxical end results [3]. While one side criticizes the lack of recognition of the intrinsic value of the country's traditional and Islamic architectural heritage; an absence of "critical regionalism" [11], the other side argues for the necessity of the direction taken during the seventies as crucial for establishing the country's current, modern 20th and 21st century environment. Skyscrapers, structures of glass and steel, car-oriented developments, shopping malls, etc., are all considered core parts of this image of modernity.

In the nineties an acute awareness of the loss of traditional and cultural values and the degeneration of cultural continuity between past and future generations, instigated the movement towards a more authentic society breaking away from the rapid, foreign transformation of the seventies. This came with the realization that architecture too needed to foster new attitudes in achieving these socio-cultural goals. Many architects found an interpretative response in Postmodernist movement, through re-using or copying elements or features of traditional, vernacular architecture in new buildings [4]. This shifting perspective can easily be observed in the built environment of the UAE which features an eclectic mix of modern, traditional or a juxtaposition of both [12]. The desire to attract tourists through a dreamy sense of a preconceived image of the "Arabian Style" has led to a fusion of various regional styles of architecture often with even Indian and Persian motifs, as opposed to purely local and vernacular architecture [6] (Fig. 3(a) and (b)).

\section{INTERPRETATIONS ABOUND}

The vernacular architecture of the UAE was deeply responsive to the desert climate, culture, landscape, lifestyle and availability of building materials [13]. Construction techniques sourced and catered to available materials such as, mud brick, palm fronds, stone and coral stone. Distinction existed in the types of housing; transient or Barasti houses were built of 


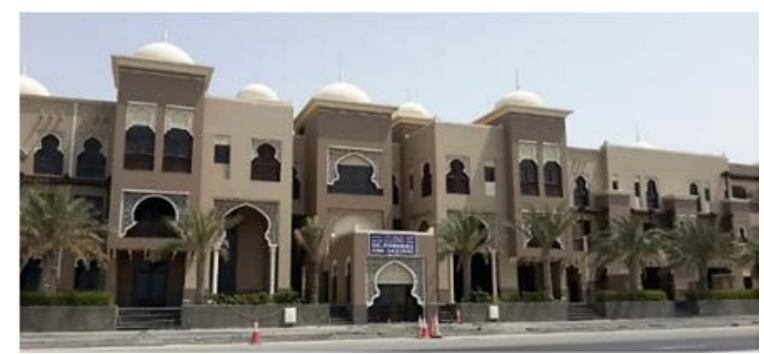

(a)

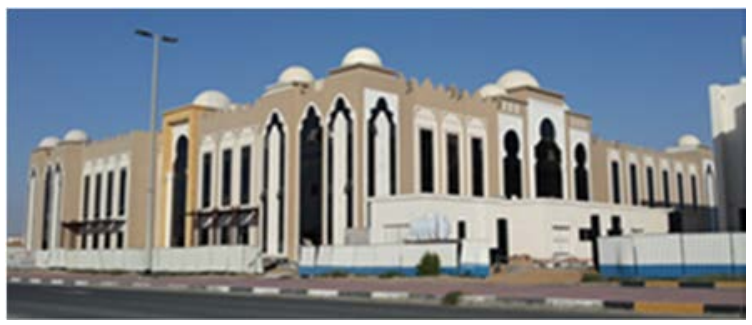

(b)

Figure 3: Arches and domes used to create an eclectic "Arabian Style" of architecture. (a) Sharjah; and (b) Ajman. (Photos: Jihad Awad, 2019.)

wood and palm fronds, while more sophisticated houses were found around wealthier, coastal towns. These houses of wealthier, coastal families were often two-storey structures built around a central courtyard. The outer elevations of the houses were often plain and bare ornamentation in the form of crenellations, sometimes featured on the upper part of walls. What was distinct about these houses were the wind catchers or Barajeel (s. Barjeel) which were extensively decorated with elaborate arches [14]. Due to an absence of mechanical cooling technologies the Barajeel; used throughout the Gulf region, were a responsive design feature to circulate air through the house particularly during harsh summer months. Wind towers or catchers are tall rectangular structures with vertical openings on all sides, the internal walls in these towers are diagonally arranged to ensure that breeze from outside is forced downwards, then up again to escape, thus creating a circulation of air through the rooms.

The prevailing traditional heritage elements; frequently re-used or copied, in modern buildings are, Barajeel, arches, domes, traditional ornaments and decorative patterns. The Barjeel has in modern times become a representative symbol of the architecture of the Gulf region [4]. Perhaps one of the reasons for this is that it is one of the loudest architectural elements that serves as a reminder of the lifestyle of the past. Another reason could be because it is the easiest to interpret contextually in any form; such as, being added as a decorative element at the top of a skyscraper or mid-rise and in any type of buildings, such as hotels, shopping malls, educational and residential buildings (Fig. 4(a)-(c)).

Due to this ease of interpretation and translation, the fusion of Barajeel is prevalent in the Postmodern interpretations of UAE's architecture. This very prevalence has transformed the Barjeel into a symbol that can be conspicuously observed in various other aspects. Urban street furniture such as, telephone boxes and items such as, charity and donation boxes, are often shaped in the form of Barjeel (Fig. 5(a)-(c)). 

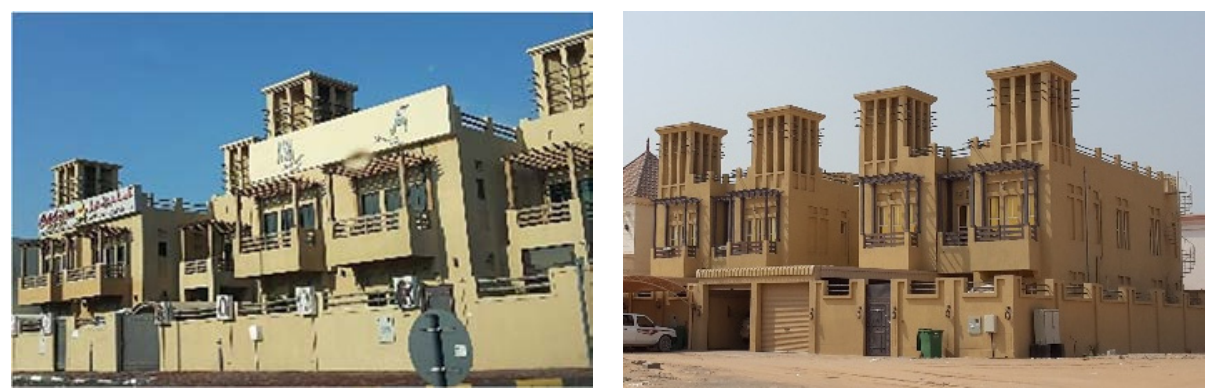

(a)
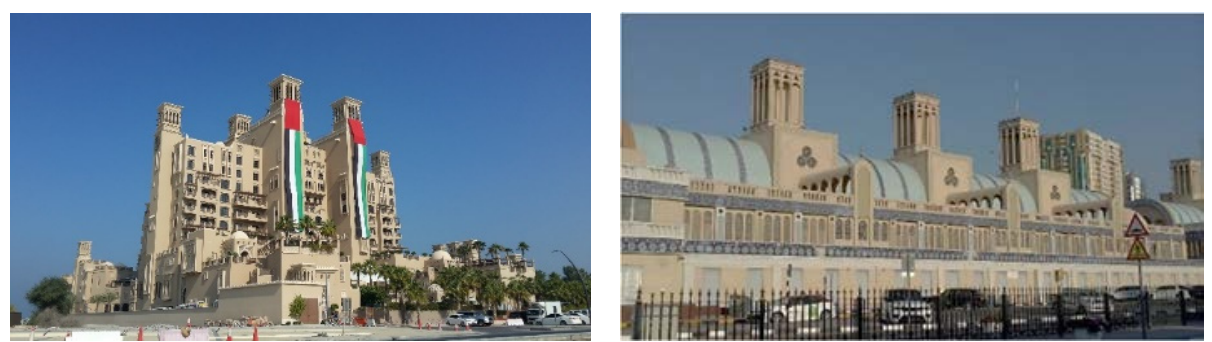

(b)
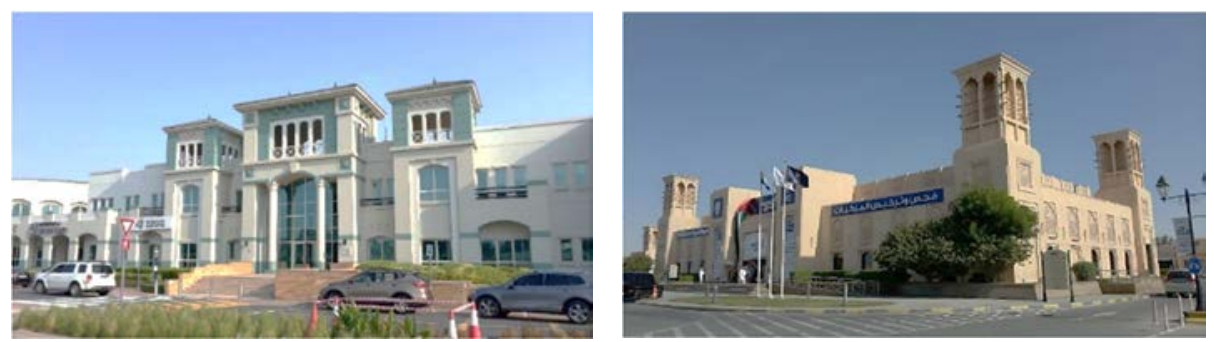

(c)

Figure 4: Decorative use of Barajeel in modern buildings with different functions and scales. (a) Residential villas: Sharjah (left), Ajman (right); (b) A luxury hotel, Sheraton, Sharjah (left), the central souq (market), Sharjah (right); and (c) An educational building, Knowledge Village, Dubai (left), a car documentation and registration center, Tasjeel, Sharjah (right). (Photos: Jihad Awad, 2019.)

This attempt to "localize" modern architecture by juxtaposing traditional architectural elements on modern buildings can be widely observed in Dubai on a larger scale. A remarkable example exists in the construction of mega leisure projects such as, Madinat Jumeirah (Fig. 2), where the architecture of the traditional house is interpreted into a conglomeration of luxury hotels and resorts. Traditional architecture has thus become a marketing tool in order to attract tourism. While the outcome is a sense of grandiosity generated from an ode to the past, the intrinsic value of vernacular architecture has been reduced to purely decorative purposes. The exploitation of traditional elements by imposing them on "modern" buildings has only served to overburden buildings with extraneous details rather than asserting an "Arabic" identity [6] (Fig. 6(a) and (b)). 


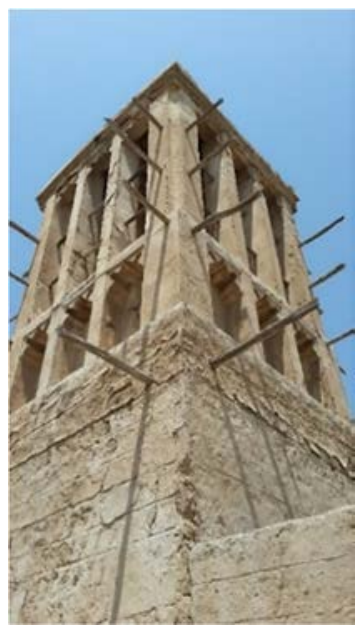

(a)

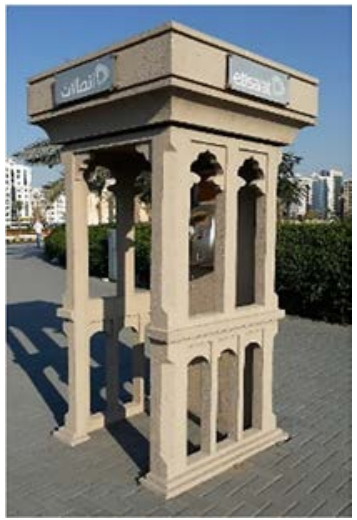

(b)

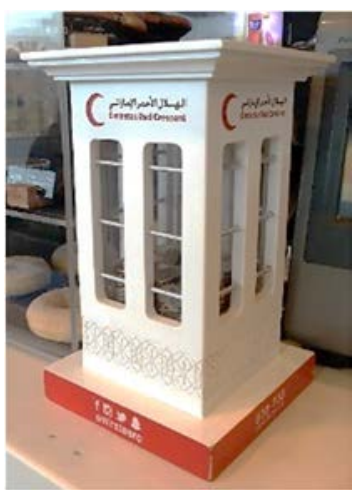

(c)

Figure 5: (a) An original, traditional Barjeel; Umm Al Quwain; (b) A telephone booth in the form of a Barjeel; and (c) A charity box designed as a Barjeel. (Photos: Jihad Awad, 2019.) 


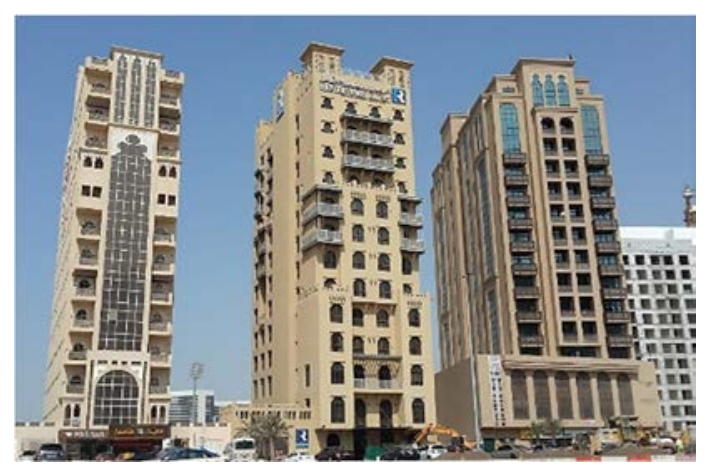

(a)

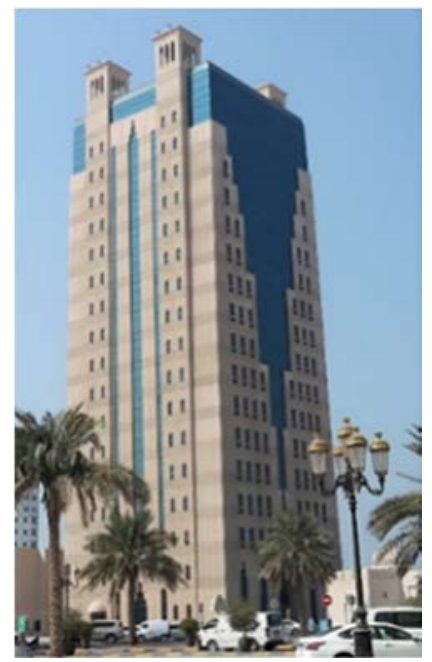

(b)

Figure 6: Juxtaposition of heritage elements with modern towers. (a) Buildings on Al Khail Road, Dubai; and (b) Offices tower in Sharjah. (Photos: Jihad Awad, 2019.)

\section{VALUING THE VERNACULAR}

Mahgoub writes that while attempts to embed elements of vernacular architecture into the design of buildings in the UAE are numerous, they are without conscience to the ethos of their original intent. The environmental and social solutions, such as, wind catchers or wooden lattice screens (mashrabiya), that were contextually reflective responses have now been reduced to mere design features [4] (Fig. 7(a) and (b)). Mitchell writes that this superficial approach is merely an excuse to term a building "regional". He further notes that there is another tendency in the architecture of the Gulf region to conceptualize the entire form of a building as an image of Gulf "heritage"; with structures that blatantly or subtly nod to sand dunes, waves, bloated falcons, etc. The potential for contemporary adaptation and supplication is ignored in the favor of fragmented imagery of heritage elements all over the built environment [5]. Numerous literal and iconic metaphors such as, the Palms and the World; to name a few, abound in Dubai [11]. 

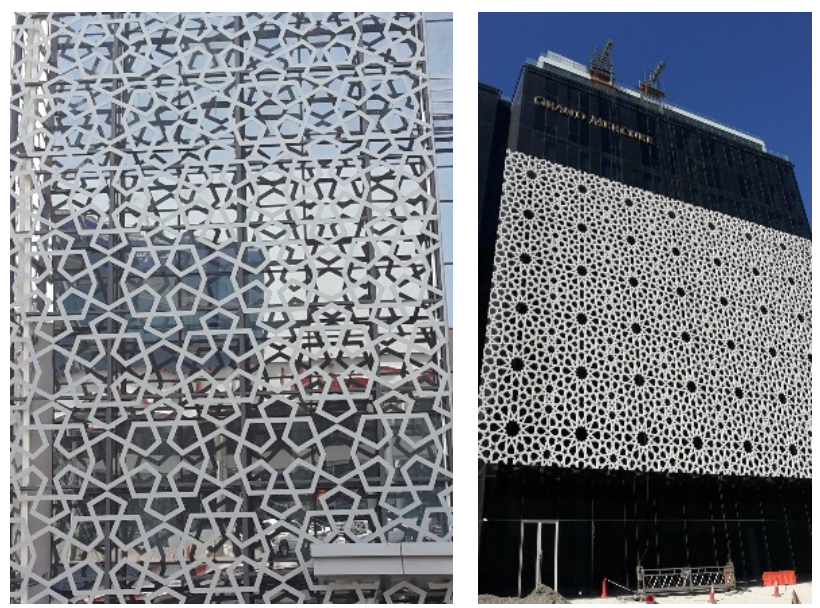

(a)

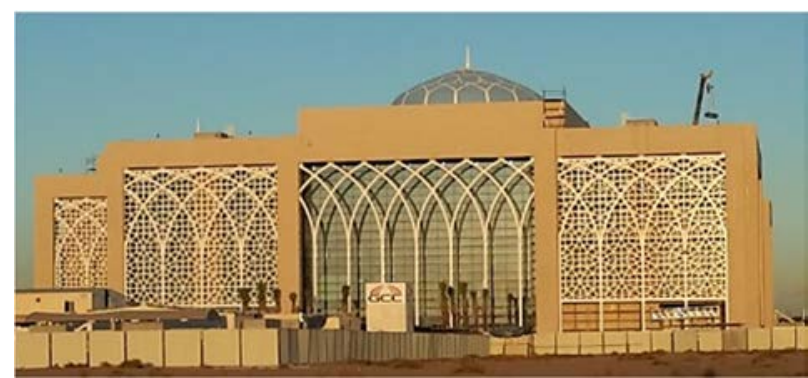

(b)

Figure 7: Use of patterns as mashrabiya for purely ornamental purposes is common sight in the UAE. (a) Two examples from Dubai; and (b) Sharjah. (Photos: Jihad Awad, 2019.)

In Abu Dhabi, a more integrative approach towards compromising the past with the present can be noted [15]; this can particularly be seen in the governmental buildings that serve as prototypes for other designs [16]. Bukhash writes that the general trend in the city's architecture in the last decade seems to be heading towards the right direction, in which architecture is "related to the culture and heritage of the region, suitable for its climate, and use modern technology and materials in its construction" [16] (Fig. 8(a)-(c)).

\section{CONCLUSION}

There exists a general consensus that the narrative of Islamic and Arab architecture has been lost in translation in modern contemporary Arab countries, not only the United Arab Emirates. Identity and heritage should be a natural and conscious product of society, not imposed on architecture capriciously [6]. Re-using and copying elements from the past ignores the value and intent of traditional architecture and is far removed from the actual "historical, social, psychological, cultural" and various other contexts it was realized in. The misinterpretation of the past in the present only serves to mislead the future architects and audience of the region, as well as globally. There is a growing need for reinterpretation of 


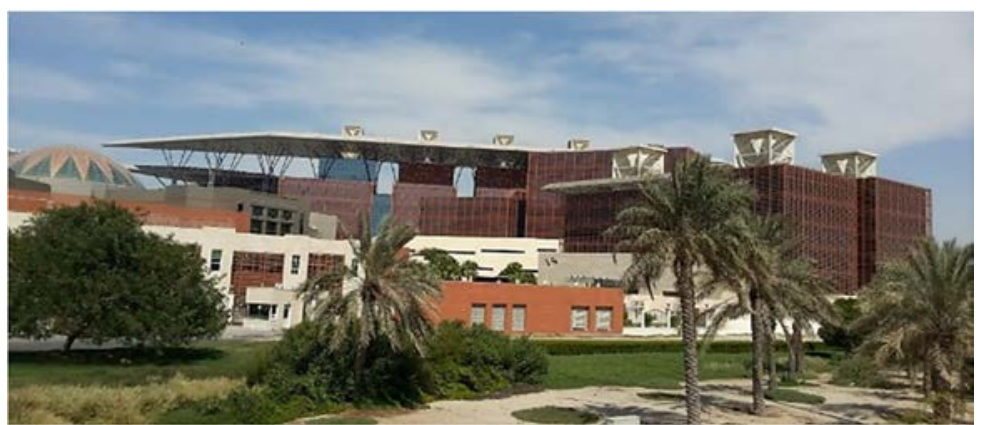

(a)

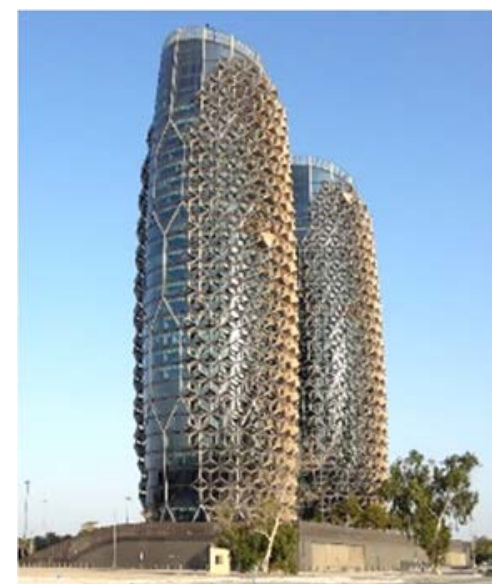

(b)

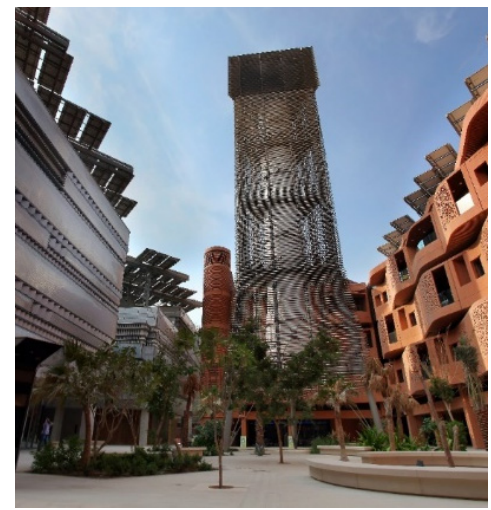

(c)

Figure 8: Some projects displaying Abu Dhabi's more integrative design approach and reinterpretative use of heritage elements. (a) Abu Dhabi Courthouse Complex, by architect Rasem Badran; (b) Al Bahr Towers; and (c) Modern Wind Tower in Masdar City, Masdar Institute. "Cooling air currents are directed through the public spaces using a contemporary interpretation of the region's traditional wind towers" [17]. (Photos: (a) and (b) Jihad Awad, 2019; (c) Shoayb Khattab.) 
Arabian architectural history and exploration of hidden values of Islamic architectural elements so that architects can use this knowledge to generate design solutions relevant to contemporary practice and architecture but rooted in vernacular authenticity [18]. Local cultures should be treated as evolutionary processes in the creation of hybrid, dynamic identities [11].

While there is a positive push towards architectural authenticity in the UAE, pure symbolic use of heritage elements is only part of an evolutionary step that could turn redundant if it does not evolve into something more substantial and crucial; contributing to the overall impact on the built environment and reflective of the vernacular principles it was founded on. Rather than copying and pasting elements of heritage, there should be growing concern on how to reinterpret these elements and their embedded values and integrate them into a fast-paced modern world that values innovation over repetition. The quality of the relationship between the new and old is the vital link in contextualizing architecture [19], rather than the imposition of elements upon each other to create a misguided sense of Postmodern architectural cacophony.

\section{ACKNOWLEDGEMENT}

The authors would like to thank Shafiya Rizwan, Research Assistant at Ajman University, for her help and efforts in preparing this paper.

\section{REFERENCES}

[1] Smithers, C. \& Monthy, F., Building on tradition. GulfNews, 2010. https://gulfnews.com/business/sectors/construction/building-on-tradition-1.666424. Accessed on: 17 May 2018.

[2] Iqbal, F., What is difference between "space" and "place" in architecture? Can we make a space into place? Can we make a space into place? www.quora.com/What-isdifference-between-space-and-place-in-architecture-Can-we-make-a-space-intoplace/answer/Faryal-Iqbal-5?utm_medium $=$ organic\&utm_source=google_rich_qa\& utm_campaign=google_rich_qa. Accessed on: 9 May 2018.

[3] Thetrypticnote, Contextualizing architectural spaces in the UAE. www.thetrypticnote.com/about. Accessed on: 5 Mar. 2020.

[4] Mahgoub, Y., Architecture of the United Arab Emirates. http://victorian.fortunecity.com/dali/428/uaearch/uaearch1.htm. 1999. Accessed on: 1 Oct. 2009.

[5] Mitchell, K., An image of Dubai, with/without: Spatial products, practices and politics in the Middle East. Bidoun and Moutamarat, Issue 4, eds B. Shumon, C. Antonia \& M. Markus, 2005.

[6] Sakr, M.M., Creating the "Arabian" architectural style. Instant Cities: Emergent Trends in Architecture and Urbanism in the Arab World, eds J. Al-Qawasmi, A. Moustafa \& K. Mitchell, CSAAR Press: Amman, Jordan, pp. 145-160, 2008.

[7] Klingmann, A., Brandscapes: Architecture in the Experience Economy, MIT Press, 2007.

[8] Gobé, M., Emotional Branding, Allworth Press: New York, p. xxviii, 2001.

[9] Wikipedia, Postmodern architecture. https://en.wikipedia.org/wiki/Postmodern_ architecture. Accessed on: 7 Mar. 2020.

[10] Haddad, E., Charles Jencks and the historiography of Post-Modernism. The Journal of Architecture, 14(4), pp. 493-510, 2009. 
[11] Al-Masri, W., Contextualizing globalization: Towards an architectural synthesis in the Gulf region. Instant Cities: Emergent Trends in Architecture and Urbanism in the Arab World, eds J. Al-Qawasmi, A. Moustafa \& K. Mitchell, CSAAR Press: Amman, Jordan, pp. 163-194, 2008.

[12] UKEssays, Modern and traditional architecture. www.ukessays.com/essays/ architecture/modern-and-traditional-architecture.php?vref $=1$. Accessed on: Nov. 2018.

[13] Wikipedia, Architecture of the United Arab Emirates. https://en.wikipedia.org/wiki/ Architecture_of the_United_Arab_Emirates. Accessed on: 7 Mar. 2020.

[14] Peterson, A., Defining traditional architecture: Architecture of the UAE. https://sites.google.com/site/architectureoftheuae/home/defining-traditionalarchitecture. Accessed on: 4 Oct. 2019.

[15] Al Radi, A., Aspects of the modern Arab/Islamic city: Architecture and urban fabric in Abu Dhabi. Architecture Re-Introduced: New Projects in Societies in Change, ed. J. Abed, The Aga Khan Award for Architecture, p. 75, 1999.

[16] Bukhash, R., Architecture re-introduced: New projects in Dubai, United Arab Emirates. Architecture Re-Introduced: New Projects in Societies in Change, ed. J. Abed, The Aga Khan Award for Architecture, pp. 77-78, 1999.

[17] Awad, J., Top International Architects: Design Concepts in Architecture, Vol. II, Universal Publisher, p. 100, 2014.

[18] Sidawi, B., Understanding the vocabulary of the Islamic architectural heritage. Global Built Environment Review, 8(2), 2013.

[19] Shukla, D., Approaches towards contextualising architecture within the U.A.E: Trends - attempts - attitudes, Conference: Manipal International Design Symposium, Dubai, April 2019. www.researchgate.net/publication/333966283_Approaches_towards_ contextualising_Architecture_within_the_UAE_Trends_Attempts_Attitudes.

Accessed on: 4 Oct. 2019. 